\title{
Process not product: Negotiating innovative interdisciplinary honours outcomes
}

\author{
Grant Ellmers and Chris Moore \\ University of Wollongong
}

\begin{abstract}
This paper describes an interdisciplinary approach to a creative arts honours collaboration that set aside a conventional approach to facilitate an experimental methodology to support greater creative innovation and knowledge acquisition. This paper examines an honours study which explored analogue and digital hybridity in board game design. The methodology employed a practice-led research approach with the Double Diamond design process model used to structure the study. A structured and critical reflective practice model was used to identify and analyse the thinking present within the creative project. A core innovation of this approach was the shift from a focus on a finalised project consisting of a separate creative work and critical thesis, to a study where the critical and creative work were still separate, but included a greater focus on process and prototyping as a means to engage with design principles, rather than a finalised product or artefact. Lessons from the collaboration are identified to inform interdisciplinary honours in the future.
\end{abstract}

Keywords: interdisciplinary honours, practice-led research, design process, design thinking, reflection

\section{Introduction}

This paper describes an interdisciplinary honours between the Digital and Social Media major and the new Visual Communication Design major (previously Graphic Design) situated in the Bachelor of Communication and Media at the University of Wollongong (UOW). The student was enrolled in the Bachelor of Creative Arts honours program, which includes a combination of a minor thesis and a creative work informed by a project- based learning approach where the project is the primary representation of the new knowledge. In this account, we describe innovation in the liminal space of the honours program. Nominally conceptualised as a senior undergraduate research and creative design program, the honours year is typically framed as a necessary stepping-stone for higher degree research but can alternatively be considered as an opportunity for an experimental approach in creative innovation and knowledge acquisition. The creative arts honours at UOW has traditionally structured the student supervision experience with a 'thesis' supervisor and 'creative' supervisor, who meet independently of each other. We began our innovation with a collective approach that supported a collaborative process between the supervisors, and between the supervisors and the student. Furthermore, the paper underscores the shift in thinking of the honours creative work as a completed and polished project towards a series of prototypes supported by a structured and critical approach to reflective practice that captures and surfaces the iterative process, informed by multiple disciplinary traditions.

Digital and social media is now a common major to be found in communication and media degrees around the world. At the University of Wollongong and other Australian universities, the discipline has responded to the changing conditions under which the media industries now operate. In 2016, the University of Wollongong dropped the 'studies' from the title of the degree in recognition of the larger paradigm change and the growing importance of emergent media within the national and global creative industries. This created the opportunity for the core of the degree to build stronger ties to the theoretical and practical directions of the degree's five majors in digital and social media, global screen media, journalism, visual communication design, and advertising and marketing, and allow for greater synthesis between the majors. This proved prescient considering the recent planned changes to the costs of humanities degrees (Hunter, 2020), as the work-integrated learning and career readiness of the renewed degree is focussed on preparing students for careers in new media and communication fields that are driven by participatory audiences that are less oriented around the 'fixed' products of the legacy media industries. The 'turn' towards emergent media has opened up new opportunities for collaboration and 
innovation, while approaches like internet studies remain vitally important, the digital and social media major has embraced the processual approach of design-focussed disciplines, creating an opportunity for an exciting and relevant interdisciplinary pedagogical approach at the undergraduate level and beyond.

The case study

The creative arts honours structure at UOW has separate theoretical and practical components, which is typical of creative arts honours programs across Australia. The theoretical component explores theories nominally associated with the subject of study, while the practical component creates a highly resolved creative product/artefact ready for exhibition or equivalent level of completion. The candidate in this instance sought to explore analogue and digital hybridity in tabletop games bringing together her major in Graphic Design, and her minor in Digital Media and Communication. This created a challenge for the supervisors to collaborate with confidence and continue to break down the clear demarcation between the theoretical and creative/practical work that had emerged for the student in the new relationship between the major and the minor. Her aim was to identify key features of the hybrid game context, and through the design of game prototypes, develop a set of design principles to inform hybrid game design. The experimental nature of this research posed a challenge to our conventional honours approach, where the study was more focused on the development of principles, rather than a completed hybrid game itself. It could be argued this study sought to engage at a more meta level, that of principles, rather than a practical outcome typically associated with the creative artefact.

It was important to introduce a methodology that would support the student in line with her objectives. In consultation with supervisors and the student, a practice-led research approach was employed with a greater emphasis on the design thinking represented within the creative design project. To support this design thinking approach the Double Diamond design process model (Design Council, 2015) was employed along with a structured and critical approach to reflective practice (Ellmers, 2015). This model informed the project as a whole and was important to the creative and reflective practice, as well as the theoretical and analytical inquiry of the critical thesis.

\section{Practice-led research}

The student sought to identify key design features present in hybrid game design and establish a set of design principles to inform further scholarly research and future industry-focused development of hybrid games. As a consequence, a practice-led research methodology was selected to structure the study. This method is concerned with the nature of practice and oriented towards research that leads to new knowledge with operational significance for that practice (Muratovski, 2016).

\section{Design thinking and the design process}

Typically, the creative project component of the honours program would result in a highly resolved creative product, in this case a hybrid analogue/digital tabletop game. However due to the primary focus on establishing a more meta level outcome, in this case a set of design principles to inform hybrid game design rather than a game itself, a different approach was needed. The creative component also served to test and refine the set of design principles introduced through the theoretical component of the study, generating feedback loops and iteration cycles between the two elements. By shifting the emphasis away from the completed and polished product to the development of project prototypes, this approach provided a space for more experimental and innovative outcomes, that while incomplete and unfinished could support knowledge development. Importantly this would scaffold the learning potential of the failures and dead ends in the iteration cycles of prototyping and feedback, which are fundamental components of the design process, and as would be the case in industry situations and challenges. This is core to the pedagogical philosophy of the Digital and Social Media major and design more broadly. This approach however comes with risks, for example an appropriate methodology must be employed to provide a scaffold for the learner to navigate through what can appear to be the chaotic nature of creative practice. Another risk is the response of examiners of both the creative work and the critical thesis, whose expectations of a traditional approach may be significantly challenged.

Identifying a clear design process model is critical in this instance. An important feature of the design process is the recognition that this creative process does not follow a linear format, but rather is a constant process of cycling and repetition of actions, requiring a flexible infrastructure allowing response to creative change (Ellmers, 2014). This study employed the Double Diamond design process model developed by the Design Council in the United Kingdom (2005). This model describes a four-stage design process identified as: Discover; Define; Develop; and Deliver. These stages are summarised in Table 1. 
The process model incorporates 'design thinking' as a form of creative strategising that emphasises solutionfocused thinking (Naiman, 2011). Generally, design thinking begins with a specific goal in mind and determines possible paths to that goal from both a practical and creative perspective, then explores these paths to determine the best course of action (Purdy \& Popan, 2016).

Where typically the creative project component would involve all four process stages, in this instance focusing primarily on the first three stages, Discover, Define, and Develop, allowed the flexibility for the candidate to test and experiment without the need to complete the fourth stage Deliver. What is imperative is that the student has a mechanism to draw meaning from the prototype designs emerging from the Develop stage. To support this the evaluation and feedback loops of the Deliver stage were maintained in the form of structured approach to reflective practice. Where typically the minor thesis is a tangential critical work deploying standardised humanities based critical theory, in this case the Double Diamond process model was used as the structure for the analytical framework of the thesis with the goal of delivering a set of recommendations for industry-focused analogue/digital hybrid design as well as the thesis itself.

\section{Table 1. Double Diamond design process model}

\begin{tabular}{|l|l|}
\hline Discover & $\begin{array}{l}\text { The design problem is identified through the exploration of a broad range of ideas, with key activities } \\
\text { that include identifying user needs, analysing market research, trends and other information sources. }\end{array}$ \\
\hline Define & $\begin{array}{l}\text { A combination of the ideas or directions identified during the Discover stage are analysed and } \\
\text { synthesised into a brief, with key activities including project development, project management, and } \\
\text { project sign-off }\end{array}$ \\
\hline Develop & $\begin{array}{l}\text { Design-led solutions are created, iterated and tested, with key activities including multi-disciplinary } \\
\text { working, visual management, development methods, and prototype testing }\end{array}$ \\
\hline Deliver & $\begin{array}{l}\text { The final design concept is taken through final testing, signed-off, produced and launched, followed by } \\
\text { product evaluation and feedback loops. }\end{array}$ \\
\hline
\end{tabular}

\section{Reflective practice}

A structured approach to reflective practice can play an important role in contributing to the student's engagement with the theory and creative practice components of the research. A structured and critical reflective practice model (Ellmers, 2015) was introduced to surface the thinking embedded in the creative project through a structured and scaffolded engagement with the design process. Reflective practice has been demonstrated to guide learners to think about their project in deliberate ways, support learners to abstract general principles from their learning experience, and play an important role in the design process as a means to explicitly engage with the thinking and understandings implicit in the activity of designing (Ellmers, 2014). The model includes steps to guide the student to describe their process, prompts them to review their process, identify critical incidents in their process, and then explain their rationale, and finally to prompt the learner to abstract general principles from their experience. This design thinking work was then included in the creative portfolio to communicate the richness of this experimental approach grounded in iterative and practice-led research.

\section{Outcomes}

To inform an evaluation of the case study, the student was interviewed, and the examiners reports were reviewed.

\section{Observations from the student}

On completion of the honours study the student was asked to reflect on her experience. She stated that being included in the discussions as the methodology was developed was very beneficial helping her to understand and take ownership on this approach. She indicated the methodology guided her as she explored game theory, and then tested this theory through the development of her creative project. She felt by developing the creative work to the first 3 stages of the Double Diamond process model and not including the fourth stage (Deliver) was important. Developing the designs through to a prototyping form, rather than a finished product or artefact, supported her to maintain a focus on design principles. The student felt the methodology helped her to make sense of the iterative nature of design and supported a successful integration of the theory and practice components of the study. That is, where the theory informed the practice, that in turn informed engagement with the theory, in a continuing looping process. 


\section{Observations from examiners}

One test for this honours approach was to see how the examiners responded. As is the policy for honours at the University of Wollongong, both an internal and external examiner was appointed. The examiners indicated the work was very professionally presented, the creative outcomes were well synthesised with the projects' aims and approaches and engaged at a sophisticated level of game design. There were concerns that some chapters did not synthesise the research into logical and well-structured arguments as well as other chapters, and that perhaps a more selective approach to the games and theories discussed would have allowed the candidate to examine them in more detail.

Of significance for this case study is the specific comments from the examiners about the approach and structure of the study. One examiner highlighted the iterative feedback looping evident within the candidate's design process and described this as a heuristic rules-of-thumb approach with no definite end-point. The examiner felt this form of thinking and approach challenged the established norms of honours level learning and what they described as a highly dogmatic approach to design theory and practice. The examiner encouraged the candidate to continue working along this vector of enquiry. They felt the experimental nature of this approach afforded the candidate a greater opportunity to explore innovative thinking around hybrid game design than perhaps more conventional approaches.

Another significant observation from the examiners was that the study was presented in a manner that clearly explained the parameters and aims of the project. This is an important and significant observation considering the experimental nature of the study's methodology. There was considerable risk that moving away from a focus on a single completed product/artefact, as is the convention, to multiple prototypes that are not as resolved, would leave the examiners confused about the study outcomes. The external examiner felt the study as a whole would have benefited from a greater integration of the theory and practice components, which interestingly reflects the views of the author around the structure of the honours program, but also suggests that while this was the ambition of the collaboration as a whole, it was not entirely realised and apparent in the assessed materials.

\section{Discussion}

It is evident from our experience and the outcomes of the study that the methodology employed ensured a high degree of flexibility to accommodate and surface the thinking and creative innovations as the work developed. This was important considering the primary focus of the creative component of the study was on developing a set of design principles to inform practice through multiple prototyping and iterative feedback loops rather than a single completed artefact as is the convention. The design process model and reflective practice proved to be important for both the candidate and the supervisors. For the candidate, this methodology served to guide her as she developed ideas and explored these through the design prototypes, and to prompt and guide the necessary critical thinking and analysis of the prototypes from which to articulate new and original hybrid analogue/digital game design principles. For the supervisors from two different disciplines it was important there was a methodology that provided a common language and structure, or common point of reference, through which to provide the different expertise in ways that were able to be effectively utilised by the candidate as she navigated her way through what can appear to be the chaotic nature of the design process. The application of a practice-led research methodology (Muratovski 2016) supported by the Double Diamond design process model (Design Council, 2005) and a structured and critical reflective framework (Ellmers ,2014) provided the necessary structure and framework to guide the study for the candidate and supervisors. The methodology successfully supported the creation of design prototypes and iterative feedback loops, the identification of the thinking embedded in the creative process, and the articulation of a series of design principles with the potential to inform the emerging discipline of hybrid game design.

This case study presented here was largely possible due to the opportunity presented by the students' selection of undergraduate subjects, her experience across both design and the digital communication and media programs, and a willingness to be part of an experimental approach to her honours study. A more systematic initiative will require institutional support in order to rebuild honours as a flexible pathway that will enable students in creative arts and media and communication to chart their own course through senior undergraduate study and beyond, whether into industry focused masters and higher degree research, academia or more life-long learning ambitions. As a result of this experience, the authors intend to pursue institutional revision to our honours programs that seeks to not only support traditional pathways to higher learning, but also increase the opportunity to engage in processual creative media works that remixes design thinking with critical theory. The aim is to produce critical/creative media hybridity in pursuit of innovation and knowledge, that is less about final polished 'products' and more about experimentation, innovation, and integration with theory. 
The success of the interdisciplinary collaboration was demonstrated at several levels, not least among them was the student's first-class honours result, which spoke not only to the student's abilities, but also to the role of the student as an equal and valued contributor and collaborator in this experiment. There is considerable potential to expand on this paper by involving the student in a more detailed investigative and ethnographic account to better account for the issues, assumptions, risks, accomplishments and challenges that were addressed, overcome and achieved through this endeavour. The broader implications of this success is the encouragement for other supervisor and student teams to similarly experiment in comparable honours programs to renegotiate the terms and parameters of the supervisor-supervised dynamic and continue to rethink and explore the potential of the creative and critical dimension of honours in both the creative arts and media and communication that is opened up by the design thinking approach.

This paper speaks to a much broader question about the future of creative and critical work at honours, masters and $\mathrm{PhD}$ level that urgently needs broader experimentation and investigation as the nature of higher education is challenged globally. It suggests a renewed attention to the question of 'what is it' that the Creative Arts and Media and Communication programs specifically need to address. In this paper we have proposed the core principles of design thinking and the design discipline more broadly as a means for crossing the interdisciplinary divide. This is an approach that allows for a greater agility and embracing of the incomplete and unfinished, the dead-ends and discovery that exists with productive failure, feed-back loops and iteration. The approach was successful in this instance and it suggests the potential of other approaches and interdisciplinary collaborations that we have not yet considered and entertained. The potential future of increased costs to undergraduate students in the humanities is only one among many of the challenges to Creative Arts and Media and Communication programs to remain current as the creative industries continue to transform in response to the participatory element of the emergent media program. In this case the design process and reflection models were compatible with the two different disciplines. As the dominant paradigm of the completed and fixed 'product' of the traditional legacy and broadcast media industries, gives way to increasingly iterative, unfinished, live, and participatory experiences with a great variety of production values and a wider range of audiences in increasingly segmented niche audiences, which have eroded the established principles of aesthetic objectivity that has historically dominated in the design and media industries. The approach proposed here required that the supervision collaboration decentered authority and supported the student to develop a critical and creative voice that was not devoted to the production of a single finished product, but oriented around industry-relevant standards, intellectual rigor, and experimentation in learning.

\section{Conclusions}

The paper describes an approach to interdisciplinary honours that shifts the primary focus from the creative product/artefact to the process underpinning the product. This shift encouraged a greater engagement with the thinking embedded in the design work and supported a practice-led research approach that supported the articulation of new knowledge with operational significance for design practice. The application of the Double Diamond design process model and a structured and critical approach to reflective practice, both played an essential role to surface the thinking typically bound within the creative product.

Due to the scale of the concise paper format the authors have focused on the core elements of the experience from their perspective to frame the speculative space for thinking about the future of interdisciplinary honours projects. The report and the results are entirely preliminary and would benefit from a more extensive review with the student, who was a major collaborator, and indeed the most important actor in the project. The paper raises questions about the potential future for senior undergraduate research, to support improved critical and creative thinking. This underscores the need for greater flexibility at the institutional and program levels in order to respond to the challenges that are facing the university system nationally and globally.

\section{References}

Design Council. (2005). The 'double diamond' design process model, http://www.designcouncil.org.uk/aboutdesign/How-designers-work/The-design-process/

Ellmers, G. (2014). Graphic Design Education: Fostering the conditions for transfer in a project-based and studio-based learning environment, through a structured and critical approach to reflective practice, $\mathrm{Ph} . \mathrm{D}$. thesis, Wollongong: University of Wollongong, Australia.

Ellmers, G. (2015). The graphic design project: employing structured and critical reflection to guide student learning, Communication Design 3(1), 62-79

Hunter, F. (2020). Cost of priority degrees to be slashed, some fees to soar in funding overhaul, The Sydney Morning Herald, June 19, https://www.smh.com.au/politics/federal/cost-of-priority-degrees-to-be-slashed- 
some- fees-to-soar-in-funding-overhaul-20200618-p553t5.html

Muratovski, G. (2016). Research for Designers: a guide to methods and practice. SAGE Publications, London

Naiman, L. (2011). Design Thinking as a Strategy for Innovation: Creativity at Work.

https://www.creativityatwork.com/design-thinkingstrategy-for-innovation/amp/ [viewed 15/08/2018]

Purdy, E. \& Popan, E. (2016). Design thinking. Salen Press Encyclopedia, Research Starters, EBSCOhost.

Ellmers, G. \& Moore, C. (2020). Process not product: negotiating innovative interdisciplinary honours outcomes. In S. Gregory, S. Warburton, \& M. Parkes (Eds.), ASCILITE's First Virtual Conference. Proceedings ASCILITE 2020 in Armidale (pp. 78-83). https://doi.org/10.14742/ascilite2020.0111

Note: All published papers are refereed, having undergone a double-blind peer-review process.

The author(s) assign a Creative Commons by attribution licence enabling others to distribute, remix, tweak, and build upon their work, even commercially, as long as credit is given to the author(s) for the original creation.

(C) Ellmers, G. \& Moore, C. 2020 